\title{
APPLICATION OF DIGITAL FILTERS TO CHECK QUALITY OF THE AUTOMATICALLY SCALED IONOGRAMS
}

\author{
Luboš Rejfek - Zbyšek Mošna - Daniel \\ Kouba - Josef Boška - Dalia Burešová *
}

\begin{abstract}
The ionospheric observatory Pruhonice serves to monitor the state of ionosphere using ground-based vertical sounding instrument - the Digisonde DPS-4D. Measured ionograms are automatically evaluated (scaled) and basic characteristics are derived. The ionograms and the scaled parameters are sent to the international databases. Especially during disturbed conditions the automatic scaling could give unreliable results. This paper presents simple method how to detect accidental errors in automatic scaling based on the parameters derived from ionograms and on an application of the finite impulse response filters.

K e y w o r d s: ionogram, F2 layer, critical frequency, virtual height, total electron content, finite impulse response filter
\end{abstract}

\section{INTRODUCTION}

The Digisonde DPS4-D installed at the observatory Pruhonice $\left(50^{\circ} \mathrm{N}, 14.5^{\circ} \mathrm{E}\right)$ is used to monitor the ionosphere with the regular interval of 15 minutes [1]. Ionograms obtained by the Digisonde are automatically scaled using the special software ARTIST which is implemented in the Digisonde and this information is used to compute profile of electron concentration [2]. Automatic scaling is based on identification of characteristic shapes of the wave reflection and the results are sent to the international databases. The data are later used for local/global mapping and forecast of the main ionospheric parameters. At times, especially during geomagnetically disturbed conditions, various problems occur despite relatively high quality of the software (eg, secondary reflection or only parts of primary reflections are identified, or presence of the sporadic E layer shields upper laying layers etc.). Manual correction of the automatically scaled ionograms is time consuming and, in general, only small amount of ionospheric data can be checked by human. The aim of our work is to facilitate the control of the quality of the automatically scaled Digisonde data by means of a preliminary identification of possibly incorrectly scaled (miscaled) ionograms. This will lead to reduction of the total number of ionograms designed for the manual correction to only ionograms with increased probability of miscalling. The ionograms identified as incorrectly scaled are manually checked and, in case of need, corrected. An example of application of the proposed method of the preliminary ionogram scaling control based on the Total Electron Content (TEC) obtained from the GNSS and the Digisonde is described in the paper [3].
The method presented in this paper is based on the using of data from the Digisonde without fusion of sensors. In this case, digital filters can be used for automatically control process of miscalled ionograms. Digital filters are described in [4] and [5]. For our purposes, we use the MA (Moving Average) filters. Filters are applied on ionospheric parameters, namely total electron content (TEC), maximum plasma frequency (critical frequency $f_{0} F 2$ ) of the $F 2$ layer, and virtual height of the $F 2$ layer $(h F 2)$.

\section{IONOSPHERE AND IONOGRAM}

Ionosphere is ionized part of the Earth atmosphere starting at the heights at about $60 \mathrm{~km}$. Ionospheric parameters (eg, critical frequency or height of ionospheric layers) are crucial for electromagnetic wave propagation [6].

Ionogram is a graph of virtual height of signal reflection plotted against the frequency of the signal. The term virtual refers to a method of computation when we assume that the signal propagates with a speed of light $c$. More realistic values of electron density are estimated from the ionogram using Digisonde standard software based on inverse methods. Fig. 1 and Fig. 2 show ionogram obtained during the night when only $F 2$ layer is present. As the ionogram was incorrectly automatically scaled (Fig. 1), we applied manual correction to get correct information (Fig. 2). Automatic scaling was wrong due to discontinuities in the $F 2$ reflection and resulted in lower value of the critical frequency $f_{0} F 2$.

\footnotetext{
* Department of Aeronomy Institute of Atmospheric Physics Czech Academy of Sciences of the Czech Republic Prague, Czech Republic lre@ufa.cas.cz, zbn@ufa.cas.cz, kouba@ufa.cas.cz, boska@ufa.cas.cz, buresd@ufa.cas.cz
} 


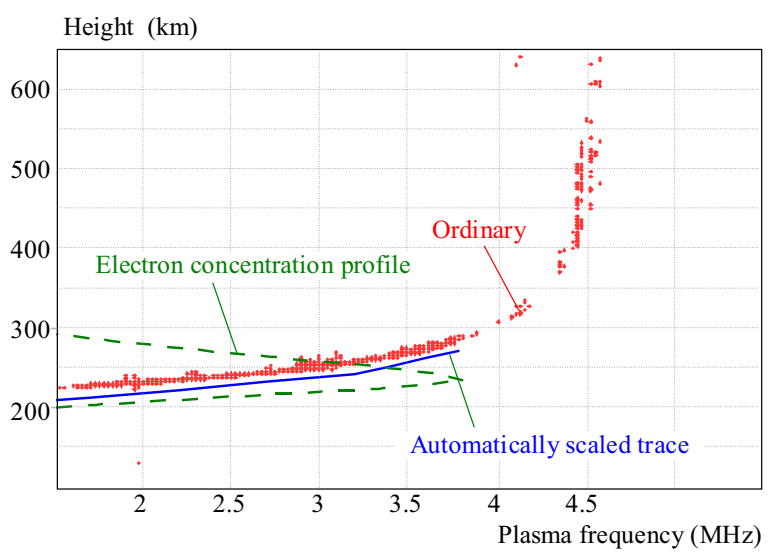

Fig. 1. An example of incorrectly automatically scaled ionogram
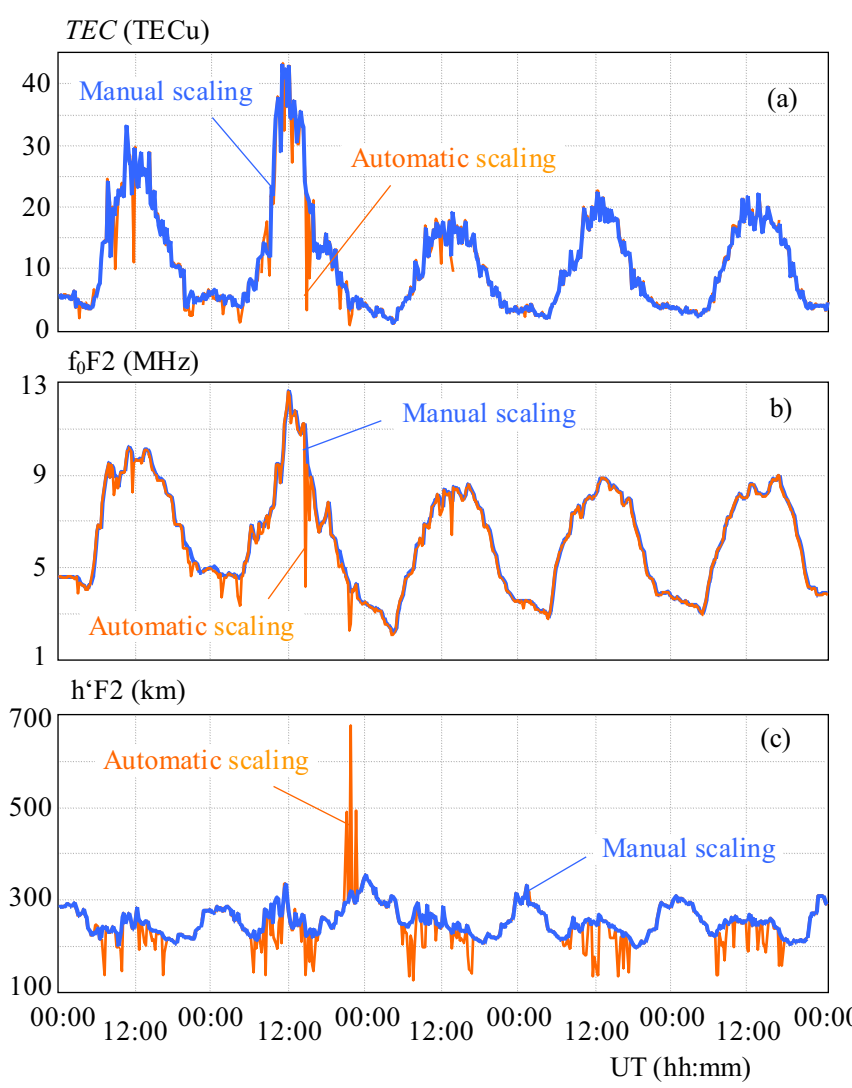

Fig. 3. Comparison of ionospheric parameters derived from automatically scaled ionograms (grey line) and manually scaled ionograms (black line). Upper panel shows the TEC derived from ionogram. Middle panel shows critical frequency. Bottom panel shows virtual reflection height. Ionograms were recorded at the Pruhonice station during 16-20 March 2013

\subsection{Total Electron Content}

Total electron content (TEC) is vertical integral of electron concentration from ground up to the height of the GPS satelites. Unit of the TEC is TECu $\left(10^{16} / \mathrm{m}^{2}\right)$. TEC can be derived from the ionogram using estimated electron concentration $N(h)$ at a particular height h between height of ground $h_{1}=0$ and the height of the satellite $h_{2}$ (1). While the electron concentration below the peak of the foF 2 layer is relatively well quantified

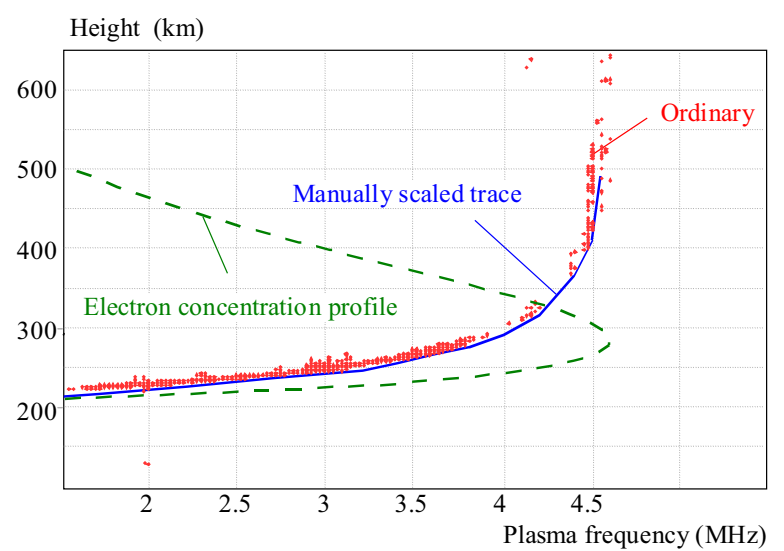

Fig. 2. The same ionogram as in Fig. 1 after manual correction

using ground measurement, the top side ionospheric ionization is derived using a model [1] with a higher level of uncertainty.

$$
T E C_{\text {Dig }}=\int_{h_{1}}^{h_{2}} N(h) \mathrm{d} h
$$

We compare the Digisonde derived TEC with the TEC obtained from the GPS data [7]. An example of the digisonde derived TEC during five days with resolution fifteen minutes is in the Fig. 3, the upper panel. In all panels of Fig. 3 black lines describe manually corrected ionograms and grey lines describe automatically scaled ionograms.

\subsection{Critical Frequency and Virtual height}

Critical frequency is maximum frequency which is vertically reflected from ionospheric plasma. It is defined using the (2), [8]

$$
f_{N}^{2}=\frac{N_{e} e^{2}}{4 \pi^{2} \varepsilon_{0} m},
$$

An example of the digisonde derived critical frequency during five days with fifteen minute resolution is given in Fig. 3 (middle diagram).

Virtual height of the ionospheric $F 2$ layer $h^{\prime} F 2$ is computed from the time of flight of the reflected signal under the assumption of its velocity equal to speed of light in vacuum (3)

$$
h^{\prime} F 2=\frac{c \Delta t}{2}
$$

where $c$ is speed of light and $\Delta t$ is the time delay between transmission of the signal and receiving of the reflected signal. Values $h^{\prime} F 2$ are obtained with 15 minute resolution and are shown in the bottom panel of the Fig. 3 .

\subsection{Detection of incorrectly scaled ionograms}

Present method uses finite impulse response (FIR) filter. The FIR filters is based on the moving average (MA) filter, which is usually used to eliminates the extreme deviations in data series(an example of using MA filter is 


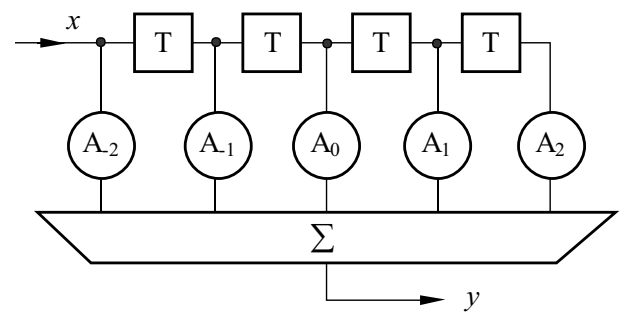

Fig. 4. Scheme of moving average filter for the fifth order

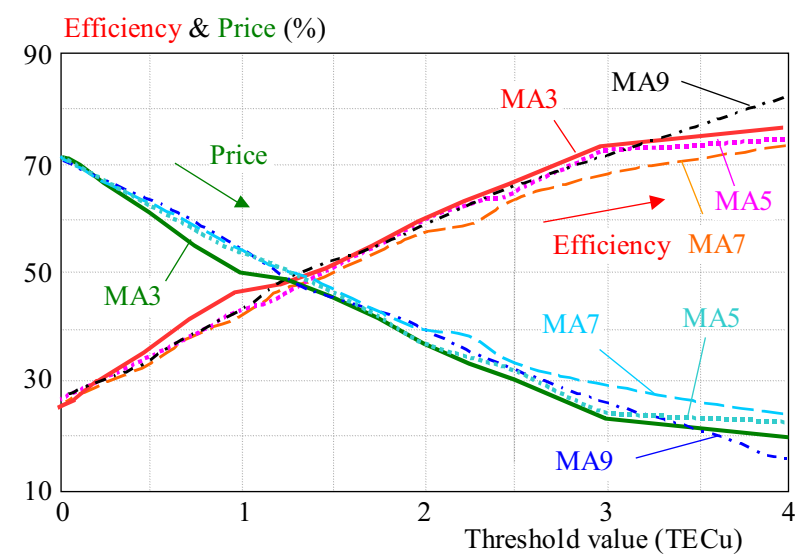

Fig. 5. TEC number of evaluated ionograms/efficiency graph

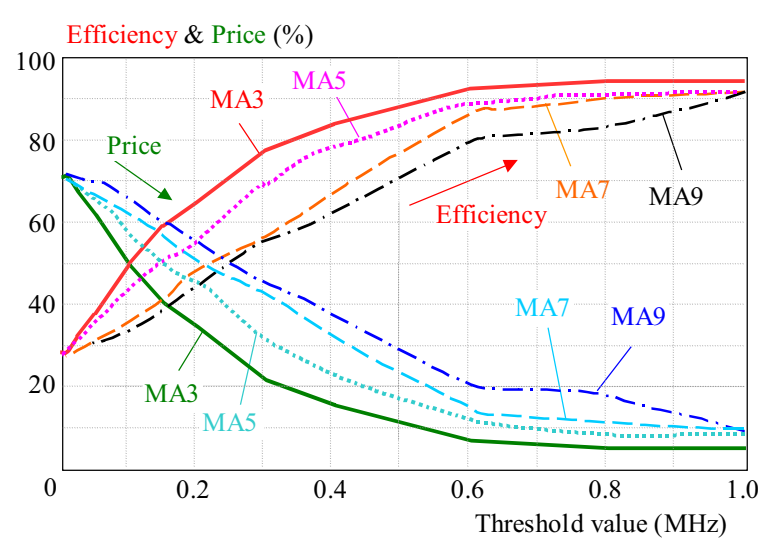

Fig. 6. $f_{0} F 2$ number of evaluated ionograms /efficiency graph

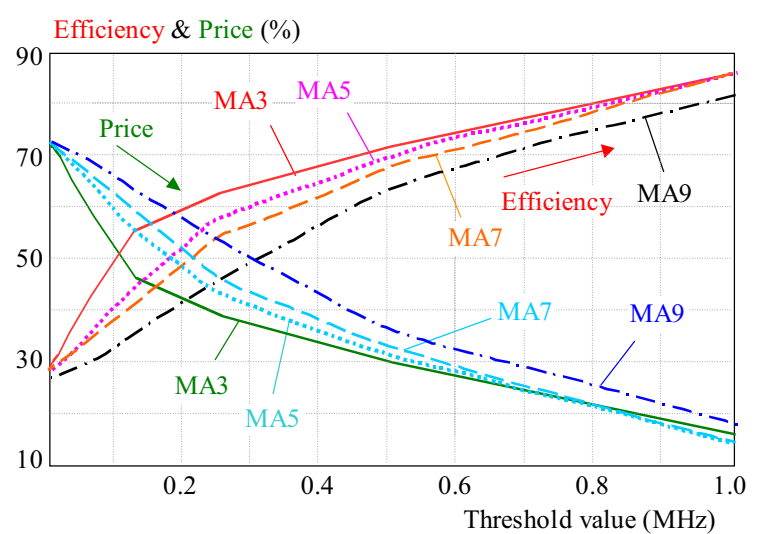

Fig. 7. $h^{\prime} F 2$ number of evaluated ionograms /efficiency graph

given in [9]). For our purpose, filtered signals are com- pared with original data. Large differences are identified in the case of probably incorrectly scaled ionograms.

We propose the following algorithm to detect the incorrectly scaled ionograms:

Signal processing is performed off-line (data are analyzed just after the measurement is finished). The equation (4) is used for calculation of the values in time line of filter of $M$-th order.

$$
y_{k}=\sum_{i=-\frac{M-1}{2}}^{\frac{M-1}{2}} A_{i} x_{k+i}
$$

The parameters $A_{i}$ are coefficients of the filter, $x_{k+i}$ are input data and $M$ is order of the filter. Scheme of the MA FIR filter for 5-th order is presented in Fig. 4. First step of applying of the algorithm is filtration of the original data. After that filtered data and original data are evaluated using the equation (5), where $V_{T}$ is threshold value. Ionogram is chosen as incorrectly scaled, if the condition (5) is satisfied and is further manually scaled. FIR filters principles are described in articles [4] and [5].

$$
x_{0}-y_{0} \geq V_{T}
$$

Threshold values must be chosen for orders of filters and for parameter of layer $F 2$. Four types of the filter orders are tested in this part of present paper $(3,5,7$ and 9). Parameters of the $F 2$-layer for the test are TEC, $f_{0} F 2$ and $h^{\prime} F 2$. Fig.5, Fig. 6 and Fig. 7 are graphs of dependence threshold values on the filter order. Black curves show efficiency in dependence on the threshold values and gray curves are for the price in dependence on the threshold. Efficiency is defined as a number of incorrectly scaled ionograms divided by the number of probably incorrectly scaled ionograms. Price is defined as a number of incorrectly suspected ionograms divided by a number of incorrectly scaled ionograms in dependence on the threshold values. Intersection of these curves is used to find threshold values for the order of filter.

Threshold values obtained from the graphs are given in Tab.1. The results indicate dependence of the threshold values on the order of used moving filter. When selecting the threshold values, the maximum number of ionograms expected to be incorrectly scaled ionogrmas was compared to be close to the equal.

Table 1. Threshold values for single ionospheric parameters

\begin{tabular}{lcccc}
\hline \multirow{2}{*}{ Parameter } & \multicolumn{4}{c}{ Threshold values } \\
& MA3 & MA5 & MA7 & MA9 \\
\hline$f_{0} F 2(\mathrm{MHz})$ & 0.1 & 0.145 & 0.21 & 0.24 \\
$h^{\prime} F 2(\mathrm{~km})$ & 5.5 & 8 & 12 & 15 \\
$T E C(\mathrm{TECu})$ & 1.4 & 1.4 & 1.4 & 1.4 \\
\hline
\end{tabular}


Table 2. Tests of the individual ionospheric parameters

\begin{tabular}{llllllc}
\hline Parameter & Filter & $\begin{array}{l}\text { Probably } \\
\text { incorrectly } \\
\text { scaled } \\
\text { ionograms }\end{array}$ & $\begin{array}{l}\text { Really } \\
\text { incorrectly } \\
\text { scaled } \\
\text { ionograms* }\end{array}$ & $\begin{array}{c}\text { save of } \\
\text { time }\end{array}$ \\
\hline \multirow{5}{*}{$f_{0} F 2$} & MA3 & 148 & $31 \%$ & 57 & $44 \%$ & $69.2 \%$ \\
& MA5 & 158 & $33 \%$ & 51 & $39 \%$ & $67.1 \%$ \\
& MA7 & 149 & $31 \%$ & 56 & $43 \%$ & $69.0 \%$ \\
& MA9 & 157 & $33 \%$ & 54 & $41 \%$ & $67.3 \%$ \\
\hline \multirow{5}{*}{$h^{\prime} F 2$} & MA3 & 219 & $46 \%$ & 19 & $15 \%$ & $54.4 \%$ \\
& MA5 & 223 & $46 \%$ & 21 & $16 \%$ & $53.5 \%$ \\
& MA7 & 194 & $40 \%$ & 28 & $21 \%$ & $59.6 \%$ \\
TEC & MA9 & 196 & $41 \%$ & 32 & $24 \%$ & $59.2 \%$ \\
\hline \multirow{5}{*}{$*$ MA3 } & 135 & $28 \%$ & 61 & $47 \%$ & $71.9 \%$ \\
& MA5 & 153 & $32 \%$ & 55 & $42 \%$ & $68.1 \%$ \\
& MA7 & 154 & $32 \%$ & 55 & $42 \%$ & $67.9 \%$ \\
& MA9 & 161 & $34 \%$ & 48 & $37 \%$ & $66.5 \%$ \\
\hline
\end{tabular}

Table 3. Tests of combination of the parameters

\begin{tabular}{|c|c|c|c|c|c|c|}
\hline \multirow[t]{2}{*}{ Parameter } & \multirow{2}{*}{$\begin{array}{l}\text { Filter } \\
\text { MA3 }\end{array}$} & \multicolumn{2}{|c|}{$\begin{array}{l}\text { Probably } \\
\text { incorrectly } \\
\text { scaled } \\
\text { ionograms }\end{array}$} & \multicolumn{2}{|c|}{$\begin{array}{l}\text { Really } \\
\text { incorrectly } \\
\text { scaled } \\
\text { ionograms* }\end{array}$} & \multirow{2}{*}{$\begin{array}{c}\begin{array}{c}\text { save of } \\
\text { time }\end{array} \\
57.3 \%\end{array}$} \\
\hline & & 205 & $43 \%$ & 41 & $31 \%$ & \\
\hline$T E C$ & MA5 & 220 & $46 \%$ & 36 & $27 \%$ & $54.2 \%$ \\
\hline \multirow{3}{*}{$f_{0} F 2$} & MA7 & 211 & $44 \%$ & 41 & $31 \%$ & $56.0 \%$ \\
\hline & MA9 & 220 & $46 \%$ & 36 & $27 \%$ & $54.2 \%$ \\
\hline & MA3 & 261 & $54 \%$ & 13 & $10 \%$ & $45.6 \%$ \\
\hline \multirow{3}{*}{$\begin{array}{l}T E C \\
h^{\prime} F 2\end{array}$} & MA5 & 266 & $55 \%$ & 13 & $10 \%$ & $44.6 \%$ \\
\hline & MA7 & 246 & $51 \%$ & 16 & $12 \%$ & $48.8 \%$ \\
\hline & MA9 & 253 & $53 \%$ & 14 & $11 \%$ & $47.3 \%$ \\
\hline \multirow{4}{*}{$\begin{array}{l}f_{0} F 2 \\
h^{\prime} F 2\end{array}$} & MA3 & 274 & $57 \%$ & 8 & $6 \%$ & $42.9 \%$ \\
\hline & MA5 & 277 & $58 \%$ & 7 & $5 \%$ & $42.3 \%$ \\
\hline & MA7 & 259 & $54 \%$ & 13 & $10 \%$ & $46.0 \%$ \\
\hline & MA9 & 258 & $54 \%$ & 14 & $11 \%$ & $46.3 \%$ \\
\hline \multirow{4}{*}{$\begin{array}{l}T E C \\
f_{0} F 2 \\
h^{\prime} F 2\end{array}$} & MA3 & 298 & $62 \%$ & 7 & $5 \%$ & $37.9 \%$ \\
\hline & MA5 & 300 & $63 \%$ & 5 & $4 \%$ & $37.5 \%$ \\
\hline & MA7 & 284 & $59 \%$ & 10 & $8 \%$ & $40.8 \%$ \\
\hline & MA9 & 287 & $60 \%$ & 10 & $8 \%$ & $40.2 \%$ \\
\hline
\end{tabular}

* not-detected

\section{TESTS OF THE METHOD}

Table 2 contains comparison results (number of probably incorrectly scaled ionograms, incorrectly scaled ionograms and time savings) with relation to single parameters and to all tested filters. Our analysis showed that the virtual height seems to be the most reliable parameter for detection of the incorrectly automatically scaled ionograms as it gives the biggest time saving. Another parameter suitable for the application of the algorithm is critical frequency of the ionospheric $F 2$ layer.
Table 3 shows results of comparison when several parameters are combined. The best result of the combination of two parameters gives the combination of virtual height and critical frequency $f_{0} F 2$. In general, the combinations of three parameters gives slightly better results than combination of two parameters, nevertheless time saving is smaller by 4.8 percent for five order of filter. The filter of the five order give better results for combination of two parameters (virtual height and critical frequency) than filters of seventh and ninth order for combination of all three tested parameters. The method described in 
this article can be applied to one ionospheric parameter, or to combination of the few parameters. Application of the method when one parameter is selected is faster, but less incorrectly scaled ionograms are detected.

\section{CONCLUSION}

The method for the evaluation of the automatically scaled ionograms by the using of elementary FIR filters was described. Tests were realized on the 5-days ionogram samples. Application of the method allows detecting incorrectly scaled ionograms and the number undetected incorrect scaling is low (at about 4\%). Different orders of the moving average filters have been tested. The best results for detection of the incorrectly scaled ionograms were obtained when applying the moving average filter of the fifth order in the combination with and for using on all selected ionospheric parameters. The proposed algorithm could be directly implemented into the computer used to control the digisonde and is able automatically indicate incorrectly scaled ionograms.

The described method fails in the case of absence of correctly scaled ionograms or appearance of data gaps in the near vicinity of the evaluated ionograms.

\section{Acknowledgement}

This study was supported by grants P209/12/2440 and 15-24688S of the Grant agency of the Czech Republic.

\section{REFERENCES}

[1] HUANG, X.-REINISCH, B. W.: Vertical Electron Density Profiles from the Digisonde Network, Advances in Space Reaserch 18 No. 6 (1996), 121-129,

DOI: $10.1016 / 0273-1177(95) 00912-4$, http:// www.sciencedirect.com/science/article/pii/0273117795009124.

[2] SAULI, P.-MOSNA, Z.-BOSKA, J.-KOUBA, D.-LASTOVICKA, J.-ALTADILL, D. : Comparison of True-Height Electron Density Profiles Derived by POLAN and NHPC Methods, Studia Geophysica et Geodetica 51 (2007), 449-459, DOI: 10.1007/s11200-007-0026-3.

[3] REJFEK, L.-MOSNA, Z.-PODOLSKA, K.-BURESOVA, D.-BOSKA, J.-KOUBA, D. : Kontrola automatického vyhodnocení ionogramů pomocí GNSS, Electroscope 7 No. 3 (2013), 5.

[4] KUMAR, B.-DUTTA, R. S. C.-SABHARWAL, S. : Interrelations between the Coefficients of FIR Digital Differentiators and other FIR Filters and a Versatile Multifunction Configuration, Signal Processing 39 No. 3 (1994), 247-262, retrieved from www.scopus.com.

[5] TSENG, C.-C.-LEE, S.-L. : Design of Linear Phase FIR Filters using Fractional Derivative Constraints, Signal Processing 92 No. 5 (2012), 1317-1327, doi: 10.1016/j. sigpro.2011.11.030.

[6] DAVIES, K.: Ionospheric Radio, London: Peter Peregrinus, 1990.

[7] RUI, T.-HONGPING, Z.-MAORONG, G.-GUANWEN, H.: A Real-Time Ionospheric Model based on GNSS Precise Point Positioning, Advances in Space Research 52 No. 6
(2013), 1125-1134, http://dx.doi.org/10.1016/j.asr.2013.06.015. (http://www.sciencedirect.com/science/article/pii/ S0273117713003657).

[8] CHEN, F. F.: Introduction to Plasma Physics, Plenum Press, New York.

[9] SINGH, N. K.-SINGH, A. K.-TRIPATHY, M. : Selection of Hidden Layer Neurons and Best Training Method for FFNN in Application of Long Term Load Forecasting, Journal of Electrical Engineering 63 No. 3 (2012), 153-161, http://www.scopus.com/inward/record.url?eid= 2-s2.0-84863840591\&partnerID $=40 \& m d 5=$ 76ba2b19b56d03609d703a0e74025ed2.

10] REINISCH, B. W.-GALKIN, I. A.-KHMYROV, G. M.KOZLOV, A. V.-BIBL, K.-LISYSYAN, I. A.-CHENEY, G. P.-HUANG, X.-KITROSSER, D. F.-PAZNUKHOV, V. V.-LUOY.-JONES, W.-STELMASH, S.-HAMEL, R.GROCHMAL, J.: The New Digisonde for Research and Monitoring Applications, Radio Sci. 44 (2009), RS0A24 doi:10.1029/2008RS004115.

Received 17 December 2014

Luboš Rejfek was born in 1985 in Chrudim, Czechoslovakia, graduated (Master degree) in 2011 at the Department of Electrical engineering of the Faculty of Electrical Engineering and Informatics at the University of Pardubice. At present he is $\mathrm{PhD}$ student at the same department and is employed at the Institute of Atmospheric Physic of the Academy of Sciences of the Czech Republic.

Zbyšek Mošna was born in 1978 in Prague. He defended his $\mathrm{PhD}$ in 2014 at the Faculty of Mathematics and Physics of the Charles University in Prague. He is engaged in the field of ionospheric variability, vertical coupling and effects of solar, geomagnetic, and neutral atmosphere activity into the ionosphere. He works at the Institute of Atmospheric Physics of the Academy of Sciences of the Czech Republic.

Daniel Kouba was born in 1975 in Chomutov, Czechoslovakia. He graduated (Master degree) in 1999 at the Department of Geophysics of the Faculty of Mathematics and Physics at the Charles University in Prague and completed his doctoral degree (PhD.) in 2014 at the Department of Surface and Plasma Science. He is employed at the Institute of Atmospheric Physics of the Academy of Sciences of the Czech Republic. In 2008 he achieved the Young Scientists Award (URSI / International Union of Radio Science).

Josef Boška was born 1947 in Prague. He graduated from the Faculty of Mathematics and Physics of the Charles University in Prague1970. From 1970 till today is working as a head of the Ionospheric Observatory Pruhonice of the Institute of Atmospheric Physics. Scientific interests: ionospheric sounding, effects of solar and geomagnetic activity on ionosphere, signatures of acoustic gravity waves in the ionosphere.

Dalia Burešová was born in 1960. She graduated from the Technical University in Kaunas, Lithuania and defended her PhD thesis at the Czech Technical University in 1992. From 1992 till now she is working at the Institute of Atmospheric Physics of the Academy of Sciences of the Czech Republic and is engaged in the field of ionospheric variability, Space weather effects on ionosphere, Troposphere-ionospheremagnetosphere coupling. 